NASA Technical Memorandum 105715

AIAA-92-3570

\title{
Full Navier-Stokes Analysis of a Two-Dimensional Mixer/Ejector Nozzle for Noise Suppression
}

James R. DeBonis

Lewis Research Center

Cleveland, Ohio

Prepared for the

28th Joint Propulsion Conference and Exhibit cosponsored by the AIAA, SAE, ASME, and ASEE Nashville, Tennessee, July 6-8, 1992 


\title{
FULL NAVIER-STOKES ANALYSIS OF A TWO-DIMENSIONAL MIXER/EJECTOR
}

\section{NOZZLE FOR NOISE SUPPRESSION}

\author{
J.R. DeBonis \\ National Aeronautics and Space Administration \\ Lewis Research Center \\ Cleveland, Ohio 44135
}

\begin{abstract}
A three-dimensional full Navier-Stokes (FNS) analysis was performed on a mixer/ejector nozzle designed to reduce the jet noise created at takeoff by a future supersonic transport. The PARC3D computational fluid dynamics (CFD) code was used to study the flow field of the nozzle. The grid that was used in the analysis consisted of approximately 900000 node points contained in eight grid blocks. Two nozzle configurations were studied: a constant area mixing section and a diverging mixing section. Data are presented for predictions of pressure, velocity, and total temperature distributions and for evaluations of internal performance and mixing effectiveness. The analysis provided good insight into the behavior of the flow.
\end{abstract}

\section{Nomenclature}

$\begin{array}{ll}\text { A } & \text { area } \\ \mathrm{C}_{\mathrm{D}} & \text { drag coefficient } \\ \mathrm{C}_{\mathrm{fg}} & \text { gross thrust coefficient } \\ \mathrm{C}_{\mathrm{p}} & \text { pressure coefficient } \\ \mathrm{L} & \text { length of mixing section } \\ \mathrm{NPR} & \text { nozzle pressure ratio } \\ \mathrm{P} & \text { pressure } \\ \mathrm{T} & \text { temperature } \\ \mathrm{V} & \text { velocity } \\ \mathrm{W} & \text { weight flow } \\ \mathrm{X} & \text { distance from chute exit } \\ \omega & \text { mixing parameter based on velocity } \\ & \end{array}$

\section{Subscripts}

amb ambient

$\begin{array}{ll}\text { bt } & \text { boattail } \\ \text { e } & \text { nozzle exit } \\ \text { mix } & \text { mixing section } \\ \text { o } & \text { total } \\ \text { p } & \text { primary } \\ \text { ref } & \text { reference } \\ \text { s } & \text { secondary }\end{array}$

\section{Introduction}

In the past decade, there has been an increasing interest in mixer/ejector nozzles because of the their noise suppression applications. These nozzles have the potential to lower jet noise without a significant thrust loss.

The basic concept of forced mixer nozzles ${ }^{1-6}$ was developed in early studies and showed the feasibility of the nozzles. More recent work ${ }^{7,8}$ has refined the designs and developed a practical system that could be employed on a future supersonic transport. Such an aircraft would have to meet Federal Aviation Regulation (FAR) 36 Stage III noise regulations.

The mixer/ejector nozzles are designed to entrain large amounts of secondary flow through an array of lobed chutes that are deployed into the primary stream. These chutes alternately misalign the primary and secondary flow with respect to the axial direction (Fig. 1). The flow misalignment causes streamwise vortices to develop at each primary-secondary flow interface. These vortices rapidly mix the two streams together before exiting the nozzle. The rapid internal mixing of the two streams lowers the total jet velocity at the nozzle exit and results in lower noise; however, high thrust is maintained because of the large amount of flow augmentation.

This paper examines a mixer/ejector nozzle at takeoff conditions using a full Navier-Stokes (FNS) computational fluid dynamics (CFD) code. The objectives of this study were to gain better insight into the nozzle 
flow field; to provide data for improvement of this design and of future nozzle designs; and to evaluate the ability of the CFD code to accurately predict mixer/ejector nozzle flow fields.

\section{$\underline{\text { Nozzle Description }}$}

The General Electric (GE) Aircraft Engine Company, under NASA Research Announcement (NRA) contract NAS-25415, has designed a two-dimensional (rectangular) mixer/ejector for noise suppression that could be used in conjunction with a mixed-flow turbofan engine. The nozzle consists of an array of 20 lobed chutes that deploy into the primary stream during takeoff and retract out of the flow path after takeoff. To avoid shocks in the flow field, the primary flow path, a convergent-divergent design, was designed to match the static pressure of the secondary stream when the two flows merge. The nozzle is intended to entrain approximately 60 percent secondary flow.

The nozzle studied in this paper (Fig. 2) is a simplified scale model of the aforementioned nozzle, and was designed to investigate the aerodynamic and mixing characteristics of the full-scale design. The general features remain the same, but the number of chutes was reduced from 20 to 10 . The actuators, seals, hinges, and other components were removed to uncomplicate the model. GE's Aerodynamics Research Lab (ARL) conducted an experimental investigation of this nozzle. Two nozzle configurations were analyzed in this computational study. The baseline configuration has a constant area mixing section $\left(A_{e} / A_{\text {mix }}=1.0\right)$. The second configuration has a diverging mixing section $\left(\mathrm{A}_{\mathrm{e}} / \mathrm{A}_{\text {mix }}=1.2\right)$. Figure 3 is a schematic of the nozzle showing terms used in the following sections.

\section{Analysis}

\section{The PARC3D Code}

The PARC3D CFD code ${ }^{9}$ was used in the analysis. The PARC code is a full Navier-Stokes multipurpose flow solver that was developed at the U.S. Air Force's Arnold Engineering Development Center (AEDC). It is a central differencing code that utilizes a BeamWarming approximate factorization algorithm. ${ }^{10}$ One of the code's distinguishing features is its ability to specify any portion of any grid surface as a boundary condition, which allows flexibility when generating a computational grid. Also, the code can solve grids that are made up of multiple grid blocks. Grid blocking allows one (1) to break up a complex domain into smaller sections, which separately use less computer memory than a single large grid and (2) to break up complex shapes into simpler components, which simplifies grid generation. Two grids that comprise a block interface do not have to be contiguous, which allows grid points across a block boundary to be reduced. A trilinear interpolation routine is used to transfer data between blocks.

The code has several options to model turbulence. The default is an algebraic model based on the method developed by Thomas, ${ }^{11}$ which can handle both wallbounded and shear layer flows. Therefore, it can be used for a wide range of problems. A two equation $\mathrm{k}-\varepsilon$ model, recently added to the code, is based on the work of Speziale ${ }^{12}$ and has been extended for use with compressible flow. The Baldwin-Lomax model, ${ }^{13}$ for wallbounded flows is also available for use in conjunction with the Thomas model for flows with both walls and shear layers. The Thomas model was used for this calculation because of its simplicity and its speed.

\section{Grid Generation}

Because of the complexity of the nozzle geometry, grid generation was a very significant portion of the overall analysis. Figure 4 shows the computational domain used in this analysis. To reduce grid size and computational time, only one-half of a chute wavelength was modeled. Symmetry planes were specified on the primary and secondary flow centerlines; consequently, the effect of the nozzle sidewalls is not considered. In other words, the grid models an infinite row of chutes. The nozzle centerline was used as a plane of symmetry; therefore, it was necessary to model only the upper half of the nozzle.

The grid used in the analysis consisted of 920671 grid points (Figs. 5 and 6 ). The grid was divided into eight smaller grid blocks to simplify grid generation. Each grid block is a component of the nozzle. For example, the chute, mixing section, and ejector inlet are all separate blocks of simpler shape than they would be if combined. Figure 6 shows an example of reduced grid points across a block boundary. The exterior flow upstream of the ejector inlet only requires resolution in the boundary layer. However, more resolution is needed near the leading edge of the ejector inlet. To avoid unnecessary high grid resolution upstream, a new coarser block was created in the upstream area, which saved approximately 67000 points.

The grid for each block was generated from detailed drawings on an IRIS workstation. The I3G/VIRGO interactive grid code ${ }^{14}$ was used to define the geometry and create the six surface grids that comprised one grid block. The three-dimensional grid volume for the block was created by inputting the surfaces to the INGRID3D code. ${ }^{15}$ The individual blocks were then combined in a post-processing step to form the complete flow-field grid. 
$\underline{\text { Results and Discussion }}$

Results were obtained on both the Cray Y-MP and the Convex C220 computers at NASA Lewis Research Center. The Cray Y-MP calculated the solution at approximately 150 iterations per hr; the Convex, at 11 iterations per hr. The Convex, although much slower in raw CPU speed, allowed the code to run continuously. The Cray Y-MP, on the other hand, used a queue system. Although the Cray was faster in terms of overall turnaround time, the difference between the two machines was not as significant as one would expect. These very low iteration speeds are due to the extremely large grid required to model the geometry. A case from an initial flow field to a converged solution requires approximately 40000 iterations. Convergence was checked by monitoring the mass flow conservation through the nozzle.

The data presented are for the following takeoff conditions; nozzle pressure ratio (NPR) of 4, primary stream total temperature of $850{ }^{\circ} \mathrm{R}$, secondary total temperature of $530^{\circ} \mathrm{R}$, and a free-stream Mach number of 0.27 .

\section{Nozzle Flow Field}

The Mach number distributions for the constant area mixing section (Figs. 7 (a) and (b)) clearly show an overexpansion and resulting shock near the nozzle exit. The secondary centerline plot shows a region of higher speed flow beginning at the start of the shroud wall and extending downward toward the nozzle exit. Also, the stagnation point for the free-stream flow can be seen on the leading edge of the ejector inlet.

The differences in total temperatures for the two streams distinguish them. Figure $8(\mathrm{a})$ shows that the temperature on the primary centerline does not decay until near the exit of the nozzle. However, the high temperatures appearing on the secondary centerline (Fig. 8(b)) indicates that some primary flow has been swept over into the secondary centerline plane by the vortex. This explains the region of high velocity in the mixing section (Fig. $7(\mathrm{~b})$ ).

Figures 9 and 10 indicate a similar flow field for the $\mathrm{A}_{\mathrm{e}} / \mathrm{A}_{\text {mix }}=1.2$ case. However, the flow separates from the shroud on the primary centerline at approximately $\mathrm{X} / \mathrm{L}=0.6$. This large recirculating region does not extend to the secondary centerline plane.

\section{Shroud Static Pressures}

Figure 11 shows the static pressure distributions on the shroud wall at both the primary and secondary flow centerlines. The areas of high pressure between
$\mathrm{X} / \mathrm{L}=0.1$ and $\mathrm{X} / \mathrm{L}=0.2$ are due to a shock impinging on the shroud. Both nozzle configurations show the nozzle is highly overexpanded. For the constant area mixing section $\left(\mathrm{A}_{\mathrm{e}} / \mathrm{A}_{\text {mix }}=1.0\right)$, the flow shocks at an axial location of $0.8 \mathrm{X} / \mathrm{L}$ to reach ambient pressure before exiting the nozzle. For the diverging mixing section $\left(\mathrm{A}_{\mathrm{e}} / \mathrm{A}_{\text {mix }}=1.2\right)$, the shock caused by overexpansion occurs at different streamwise positions for the two spanwise locations plotted. The difference in shock location occurs because the recirculating region does not extend over the entire width of the nozzle.

\section{Primary and Secondary Flow Mixing}

Figure 12 is an illustration of the area for which quantities are plotted in Figs. 13 to 16 . The most important attribute of a mixer/ejector nozzle is its mixing effectiveness. The extent to which the two streams mix directly determines both noise characteristics and ejector performance. The enhanced mixing of the two streams in this nozzle is caused by the vortices created at the chute exits because of the misalignment of the primary and secondary flows (Fig. 13(a)). The ejector flow is drawn downward through the chutes. The primary stream flowing between the chutes is directed slightly upward. Downstream of the chute exit, the primary flow migrates upward and then begins to roll over and down into the secondary flow plane. The vortex forms near the top of the mixing section close to the shroud wall. As the flow moves through the nozzle, the center of the vortex translates downward and the size of the vortex grows. The motion of the higher momentum primary flow dominates and determines the motion of the vortex. DeJoode and Patankar ${ }^{16}$ show, in a hypermixing nozzle, that symmetric vortices are generated when the two flows have the same momentum. Figure 13(b) also shows the formation of a small set of vortices at the shroud wall on the secondary flow centerline. These vortices persist throughout the nozzle.

Total temperature contours (Fig. 14) are useful in visualizing the extent of mixing that has occurred. A mushroom-shaped plume of primary flow forms at the secondary flow centerline, downstream of the chute exit. This shape defines the vortex and the tip of the primary stream as it mixes with the secondary flow and is typical of mixer nozzle flow fields. ${ }^{17}$ At the nozzle exit, the primary flow extends down near the axis of symmetry. A considerable amount of mixing has taken place; however, significant amounts of unmixed primary flow that have migrated up near the shroud wall remain.

For the diverging shroud, the flow behaves similarly to that of the constant area mixing section. However, the recirculating region at the nozzle exit forces the vortex away from the wall (Fig. 15). The total temperature contours (Fig. 16) show the recirculating 
region at the exit, where the lower temperature ambient flow has been pulled into the region. The area extends over the entire primary flow path.

Bevilaqua ${ }^{2}$ proposed using the flatness of the velocity profile as a quantitative measure of the extent of mixing. This mixing parameter is defined as

$$
\beta \equiv \frac{\int \mathrm{V}^{2} \mathrm{dA}}{\langle\mathrm{V}\rangle^{2} \mathrm{~A}}
$$

where the average velocity is given by

$$
\langle\mathrm{V}\rangle=\frac{\int \mathrm{Vd} A}{\mathrm{~A}}
$$

For uniform velocity profile the parameter is $\beta=1.0$. The unmixed flow at the chute exit plane has a parameter of $\beta=1.58$. At the exit of the nozzle, the values for the $\mathrm{A}_{\mathrm{e}} / \mathrm{A}_{\text {mix }}=1.0$ and $\mathrm{A}_{\mathrm{e}} / \mathrm{A}_{\text {mix }}=1.2$ configurations are $\beta=1.19$ and $\beta=1.30$, respectively. Because the velocity field is dependent on more than just the extent of mixing, problems can arise when using this parameter to analyze the mixing of the two streams throughout the nozzle-mixing section. However, the total temperature field depends only on the mixing. In flows where the primary and secondary streams differ in total temperatures, this fact can be used to define a mixing parameter.

$$
\omega \equiv \frac{\int\left|\mathrm{T}_{\mathrm{o}}-\mathrm{T}_{\mathrm{o}_{\mathrm{ave}}}\right| \mathrm{dA}}{\left[\int\left|\mathrm{T}_{\mathrm{o}}-\mathrm{T}_{\mathrm{o}_{\mathrm{ave}}}\right| \mathrm{dA}\right]_{\mathrm{ref}}}
$$

The chute exit plane was used as the reference plane. A value of 1 for $\omega$ corresponds to no mixing; a value of 0 , to complete mixing. Figure 17 shows the increase in mixing through the nozzle-mixing section. The mixing appears to occur at a constant rate. At the nozzle exit plane, the flows are 45- and 40-percent mixed for the constant area and diverging cases, respectively. Extrapolating from the data, complete mixing of the two streams would occur at an X/L of approximately 2.3 . This indicates that if complete mixing is desired, very long and, consequently, very heavy nozzles would be required.

\section{Nozzle Performance}

Table 1 summarizes the major performance characteristics of the two configurations. The predicted ejector pumping corresponds well with the design value and is similar for both nozzles. However, the diverging shroud configuration was expected to pump larger amounts of flow. ${ }^{1}$ Two possible causes for this behavior are (1) the recirculation region at the exit effectively reduces the nozzle exit area and (2) the secondary flow may have choked and the area increase downstream was not able to influence the pumping.

Gross thrust performance is presented as a variation of the baseline configuration. The separated region in the diverging case caused a loss of thrust from the $\mathrm{A}_{\mathrm{e}} / \mathrm{A}_{\text {mix }}=1.0$ case.

Because of the large boattail angles at takeoff conditions, the pressure drag on the boattail may be a concern. Pressure coefficient on the boattail is plotted in Fig. 18. These curves are typical of flows over boattails. $^{18}$ The boattail angle is larger for the $A_{e} / A_{\text {mix }}=1.0$ case, which causes the lower surface pressures and, therefore, higher drag.

\section{Conclusions}

Mixer/ejector nozzles have the potential to lower jet noise without significant thrust loss, A full NavierStokes (FNS) analysis of a rectangular mixer/ejector nozzle was performed. The objective was to gain better insight into the complex flow field and to provide data for improvement of the design.

The PARC3D code was used for the analysis. The grid that was used consisted of 920671 grid points in 8 grid blocks. The complex nozzle geometry required a large grid generation effort. Because of the large grid size, iteration speed was very slow. Two configurations of the nozzle, a constant area and a diverging mixing section, were studied at takeoff conditions.

The flow field was dominated by a system of large streamwise vortices. These vortices were created at the exit of mixer/ejector chutes as a result of the misalignment of the primary and secondary flows. The vortices sweep the primary flow into the secondary stream, which increases the mixing between the two streams.

The flow in both configurations overexpanded and shocked near the nozzle exit. For the diverging shroud case, the flow separated from the shroud and caused a large recirculating region which contributed to poorer thrust performance than occurred in the constant area mixing section.

\section{$\underline{\text { References }}$}

1. Bevilaqua, P. M., "Evaluation of Hypermixing for Thrust Augmenting Ejectors," Journal of Aircraft, Vol. 11, 1974, pp. 348-354. 
2. Bevilaqua, P. M., "Analytical Description of Hypermixing and Test of an Improved Nozzle," Journal of Aircraft, Vol. 13, 1976, pp. 43-48.

3. Paynter, G. C., Birch, S. C., Spalding D. B., and Tatchell, D. G., "An Experimental and Numerical Study of the 3-D Mixing Flows of a Turbofan Engine Exhaust System," AIAA Paper 77-204, Jan. 1977.

4. Presz, W. M., Morin, B. L., and Gousy, R. G., "Forced Mixer Lobes in Ejector Designs," Journal of Propulsion and Power, Vol. 4, No. 4, July-Aug. 1988, pp. 350-355.

5. Patterson, R. W., "Turbofan Mixer Nozzle Flow Field - A Benchmark Experimental Study," Journal of Engineering for Gas Turbines and Power, Vol. 106, July 1984, pp. 692-698.

6. Tillman, T. G., and Paterson, R. W., "Supersonic Nozzle Mixer Ejector," AIAA Paper 89-2925, July 1989.

7. Tillman, T. G., Patrick, W. P., and Paterson, R. W., "Enhanced Mixing of Supersonic Jets," AIAA Paper 88-3002, July 1988.

8. Lord, W. K., Jones, C. W., Stern, A. M., Head, V. L., and Krejsa, E. A., "Mixer-Ejector Nozzle for Jet Noise Suppression,” AIAA Paper 90-1909, July 1990.

9. Cooper, G. and Sirbaugh, J., "The PARC Distinction: A Practical Flow Simulator," AIAA Paper 90-2002, July 1990.

10. Beam, R. M., and Warming, R. F., "An Implicit Finite-Difference Algorithm for Hyperbolic Systems in Conservation-Law Form - Application to
Eulerian Gasdynamic Equations," Journal of Computational Physics, Vol. 22, No. 1, Sep. 1976, pp. 87-110.

11. Thomas, P. D., "Numerical Method for Predicting Flow Characteristics and Performance of Nonaxisymmetric Nozzles-Theory," NASA CR-3147, 1979.

12. Speziale, C. G., Ridha, A., and Anderson, E. C., "A Critical Evaluation of Two-Equation Models for Near Wall Turbulence," NASA CR-182068, 1990.

13. Baldwin, B. S., and Lomax, H., "Thin Layer Approximation and Algebraic Model for Separated Turbulent Flows," AIAA Paper 78-257, Jan. 1978.

14. Amdahl, D., "Interactive Multi-Block Grid Generation." Numerical Grid Generation in Computational Fluid Dynamics, Pine Ridge Press, Swansea, Wales, VK, 1988, pp. 579-588.

15. Soni, B. K., "Two- and Three-Dimensional Grid Generation for Internal Flow Applications of Computational Fluid Dynamics," AIAA Paper 85-1526, July 1985 .

16. DeJoode, A. D., and Patankar, S. V., "Prediction of Three-Dimensional Turbulent Mixing in an Ejector," AIAA Journal, Vol. 16, Jan. 1978 pp. 145-150,

17. Malecki, R., Mityas, S., and Lord, W., "NavierStokes Analysis of an "Ejector and Mixer-Ejector Operating at Pressure Ratios in the Range of 2-4," AIAA Paper 90-2730, July 1990.

18. Shrewsbury, G. D., "Effect of Boattail Juncture Shape on Pressure Drag Coefficients of Isolated Afterbodies," NASA TM X-1517, 1968.

Table 1.-Nozzle Performance

\begin{tabular}{|l|c|c|}
\hline \multirow{2}{*}{ Characteristic } & \multicolumn{2}{c|}{ Mixing section configuration } \\
\cline { 2 - 3 } & $\begin{array}{c}\text { Constant area, } \\
\mathrm{A}_{\mathrm{e}} / \mathrm{A}_{\text {mix }}=1.0\end{array}$ & $\begin{array}{c}\text { Diverging, } \\
\mathrm{A}_{\mathrm{e}} / \mathrm{A}_{\text {mix }}=1.2\end{array}$ \\
\hline Mixing parameter, $\beta$ & 1.1985 & 1.3111 \\
\hline Mixing parameter, $\omega$ & 0.5516 & 0.6015 \\
\hline Ejector pumping $\mathrm{W}_{\mathrm{s}} / \mathrm{W}_{\mathrm{p}}$ & 0.6090 & 0.6110 \\
\hline Gross thrust coefficient, $\mathrm{C}_{\mathrm{fg}}$ & Baseline & -6.74 percent \\
\hline Drag coefficient (boattail), $\mathrm{C}_{\mathrm{D}_{\mathrm{bt}}}$ & Baseline & -99.56 percent \\
\hline
\end{tabular}




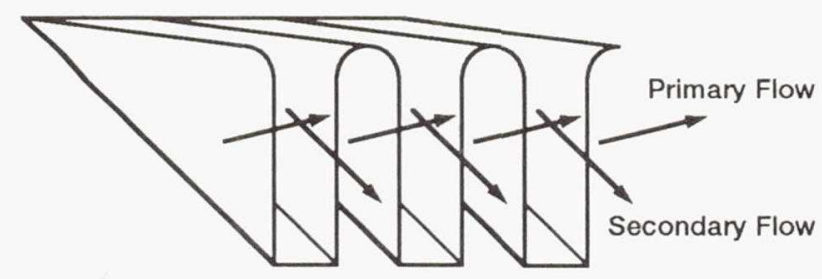

Figure 1.-Typical mixer/ejector chute geometry.

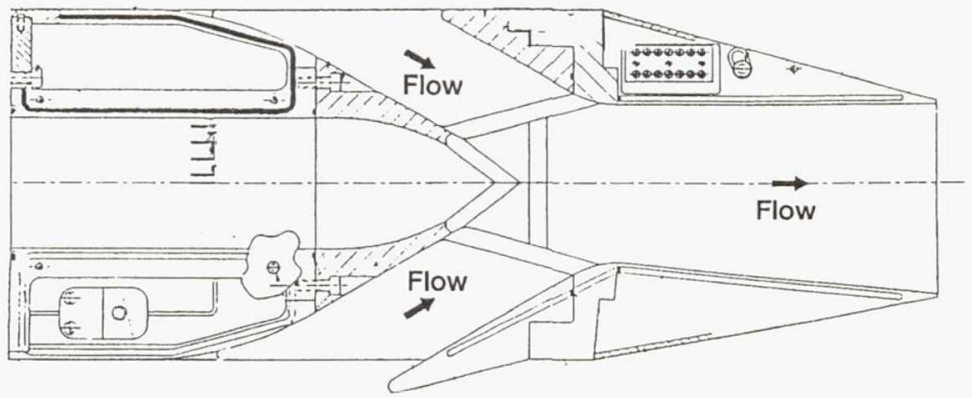

Figure 2.-Schematic of experimental model.

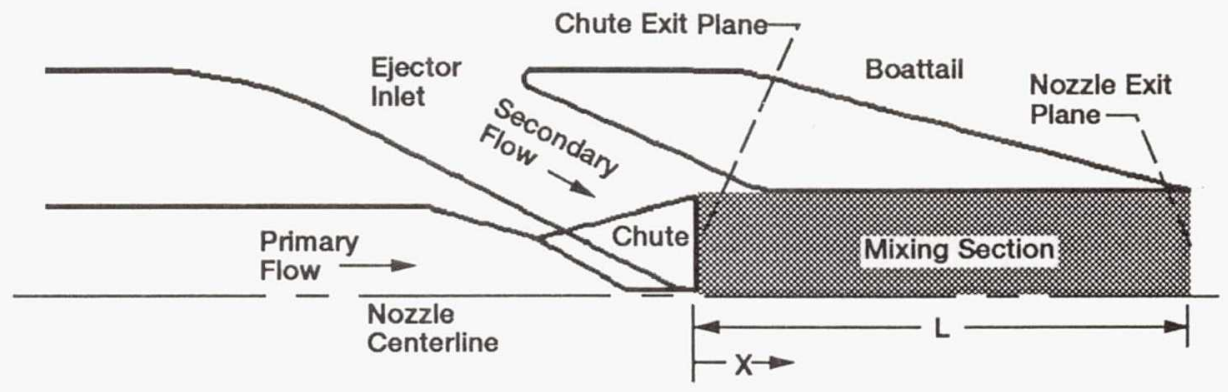

Figure 3.-Nozzle Schematic.

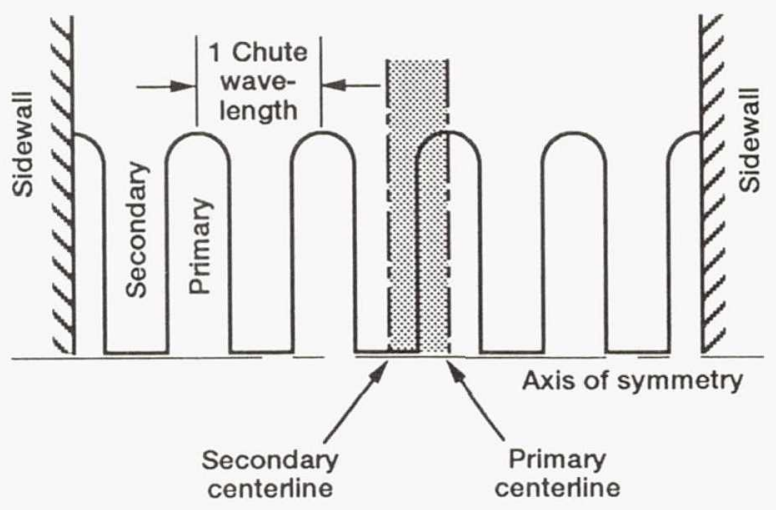

Figure 4.-Computational domain. 


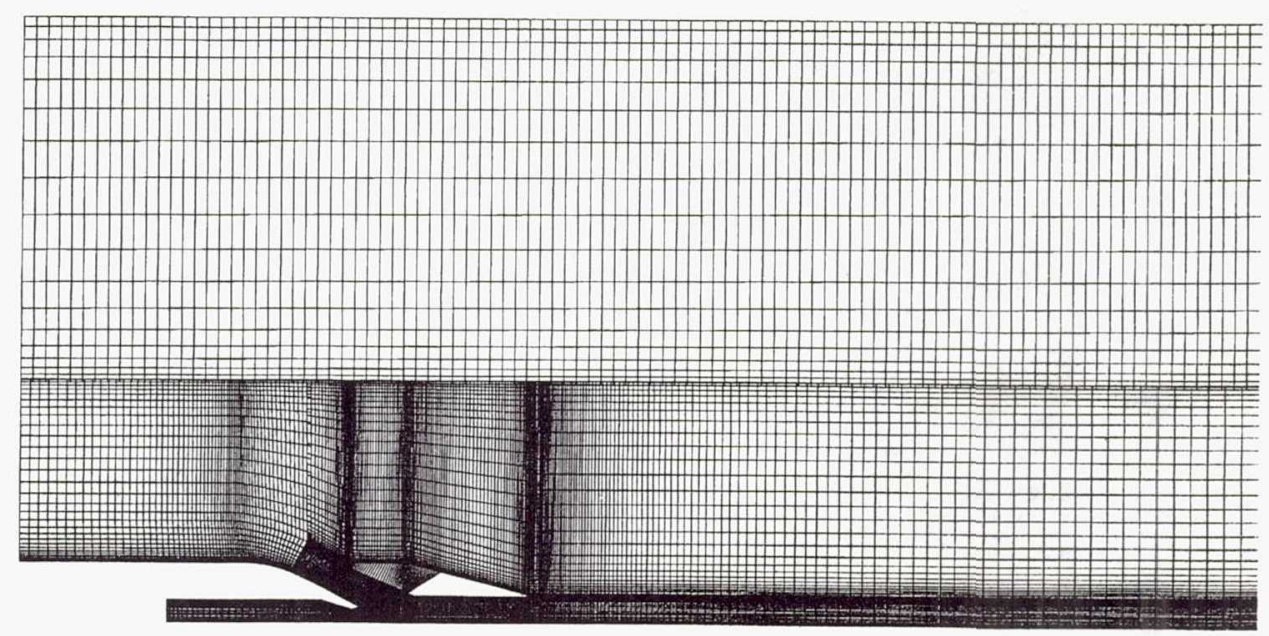

Figure 5.-Computational grid.

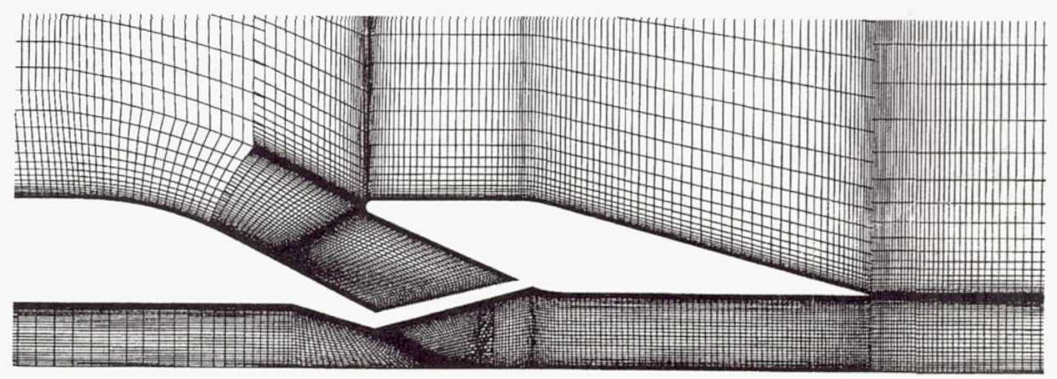

(a) Primary centerline $\left(A_{e} / A_{\text {mix }}=1.0\right)$.

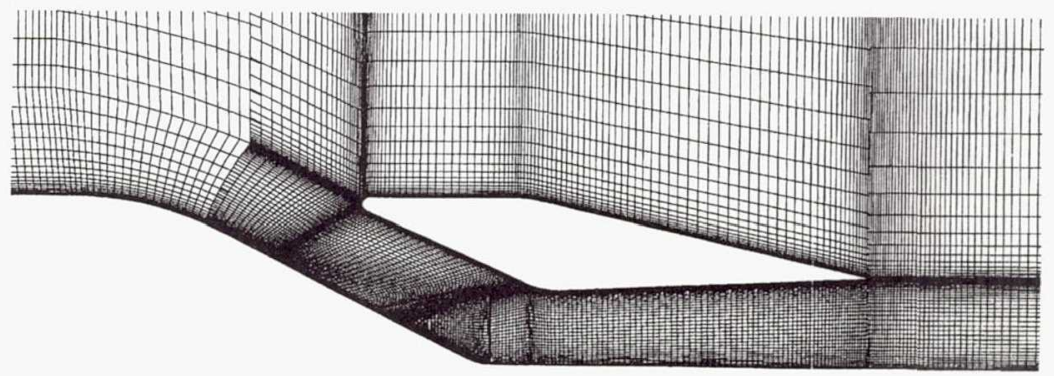

(b) Secondary centerline $\left(A_{e} / A_{\text {mix }}=1.2\right)$.

Figure 6.-Computational grid nozzle detail. 


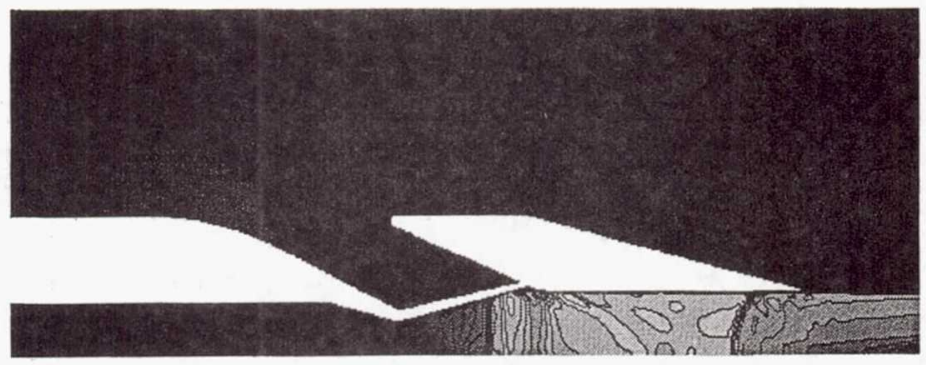

(a) Primary centerline.

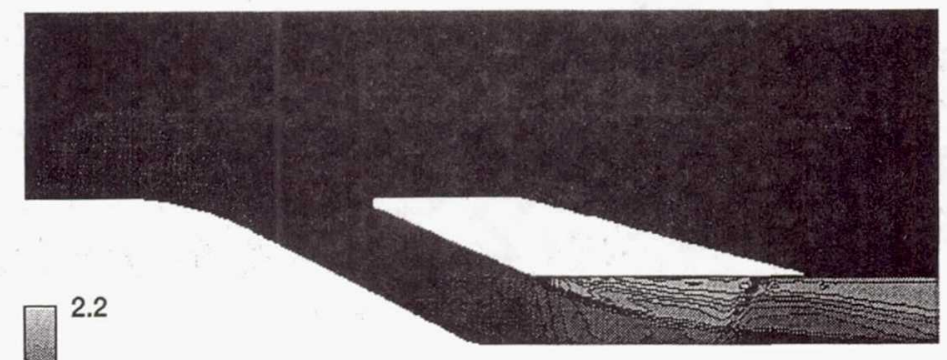

(b) Secondary centerline.

0.0 Figure 7.-Mach number contours $\left(A_{\mathrm{e}} / A_{\mathrm{mix}}=1.0\right)$.

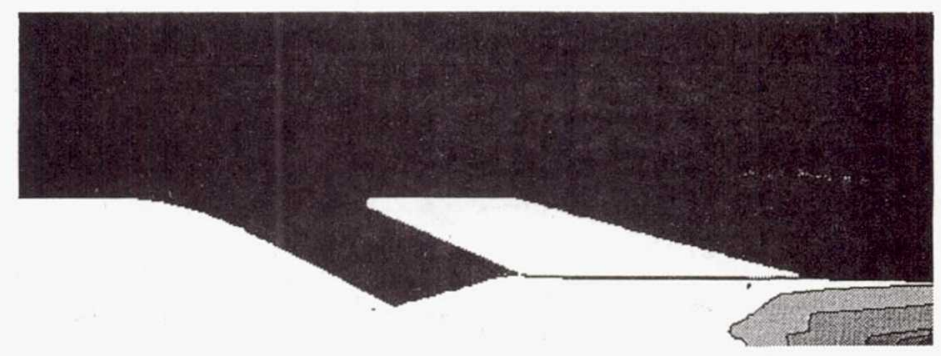

(a) Primary centerline.

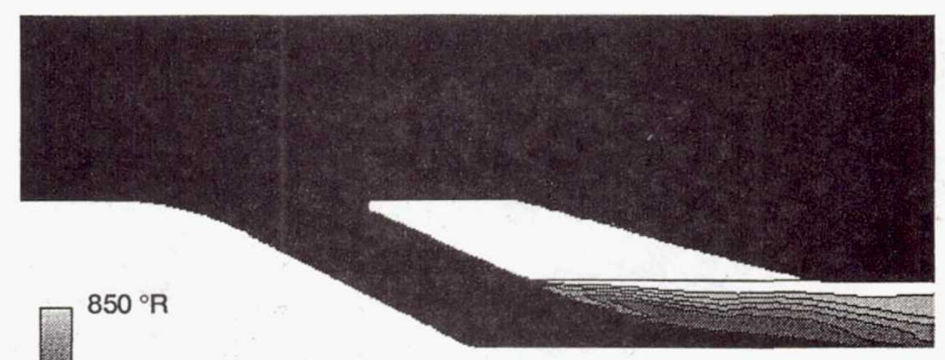

(b) Secondary centerline.

$530^{\circ} \mathrm{R}$

Figure 8. - Total temperature contours $\left(A_{e} / A_{\text {mix }}=1.0\right)$. 


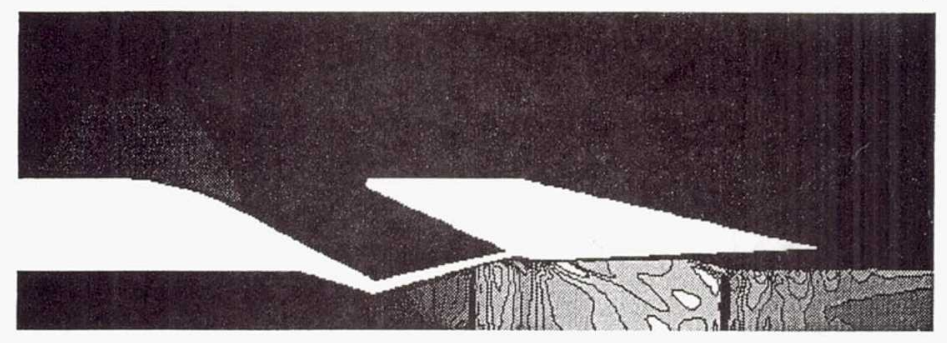

(a) Primary centerline.

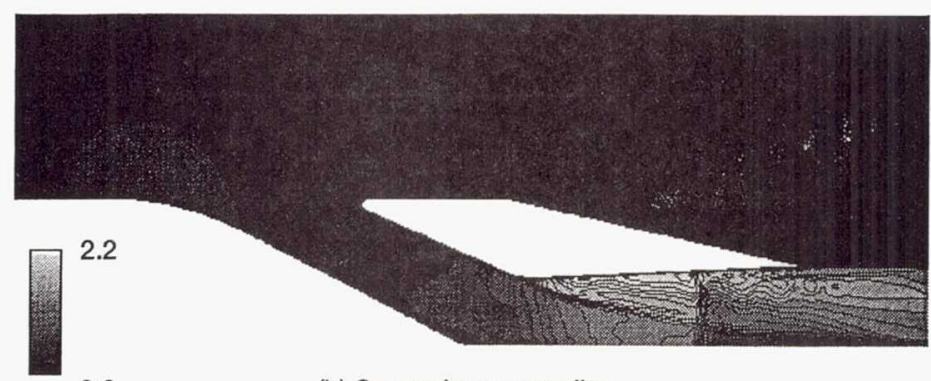

0.0

(b) Secondary centerline.

Figure 9.- Mach number contours $\left(A_{\mathrm{e}} / A_{\text {mix }}=1.2\right)$.

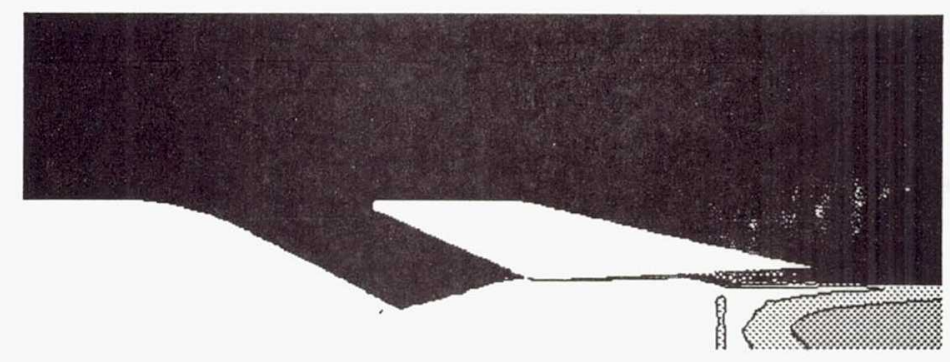

(a) Primary centerline.

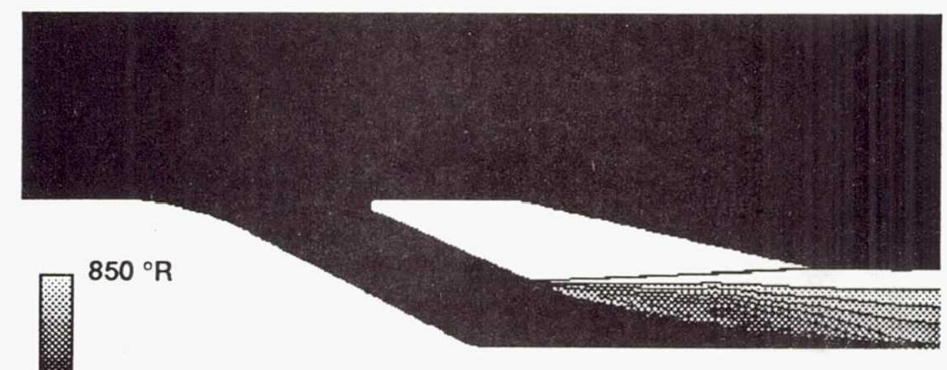

$530^{\circ} \mathrm{R}$

(b) Secondary centerline.

Figure 10. - Total temperature contours $\left(A_{e} / A_{\text {mix }}=1.2\right)$. 


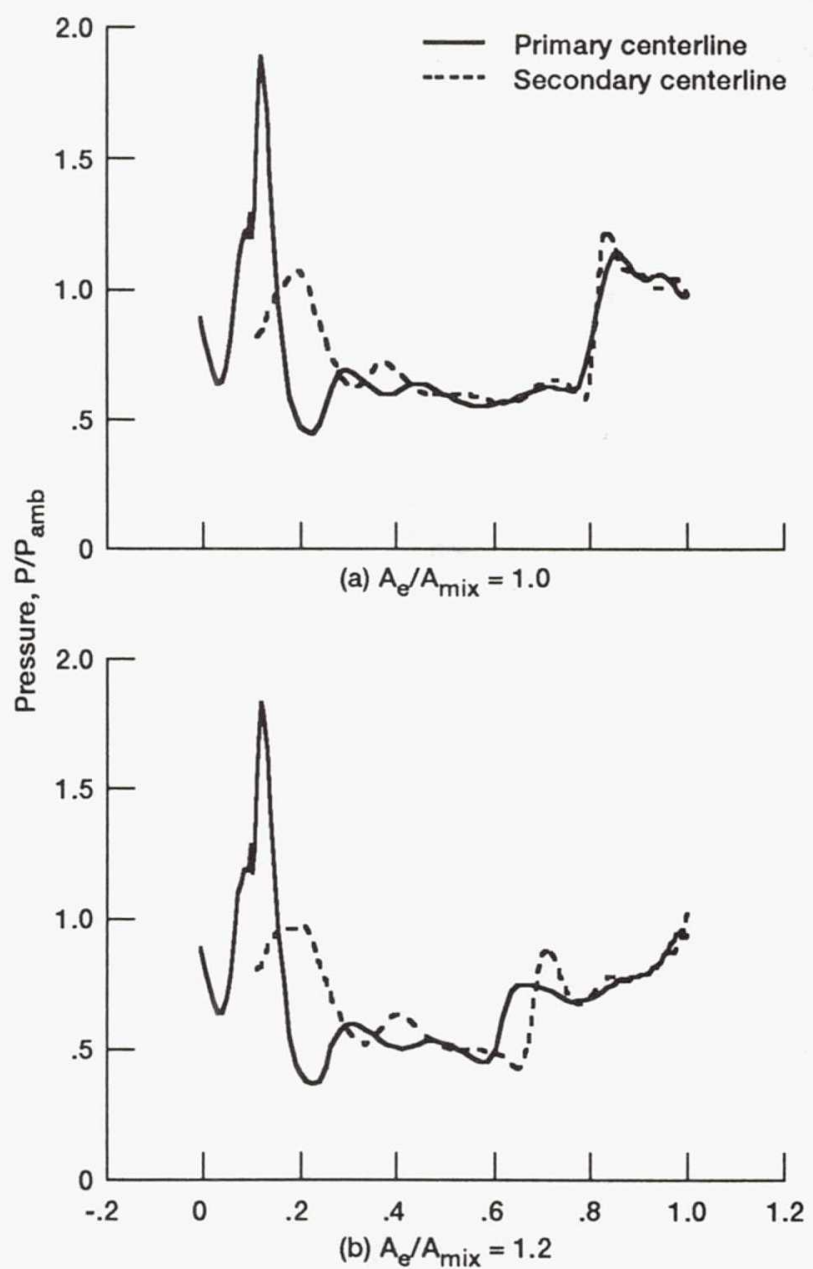

Axial position, $X / L$

Figure 11.-Shroud static pressures mixing section.

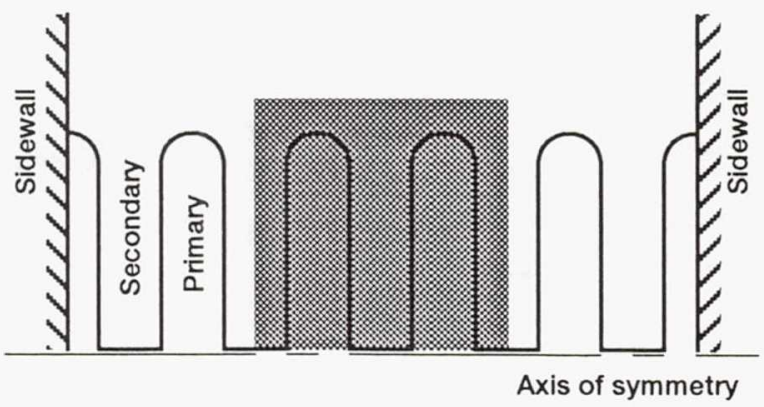

Figure 12.-Area of mixing section. 


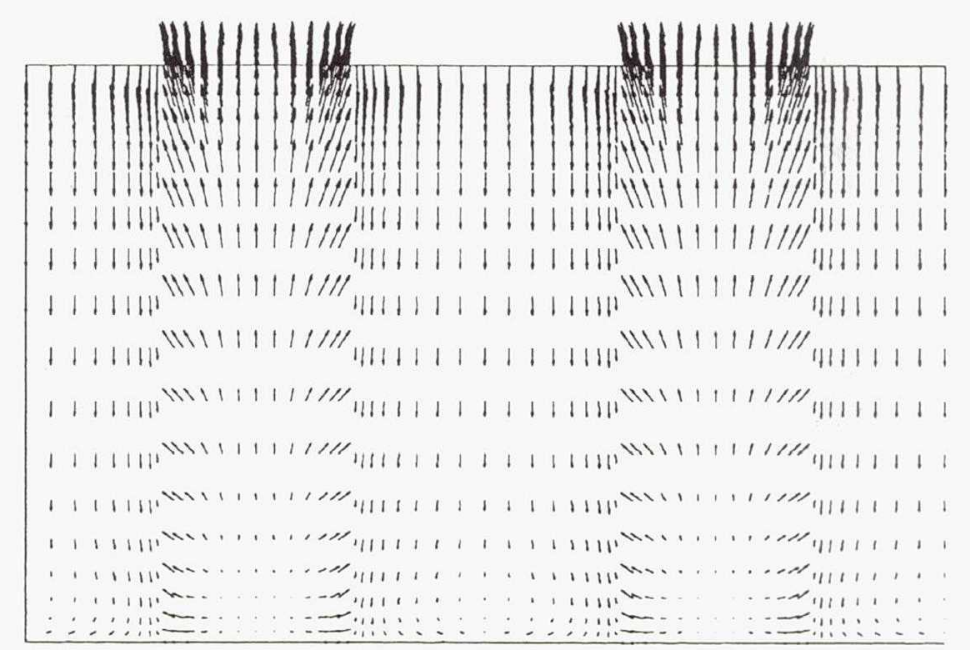

(a) $X / L=0.0$.

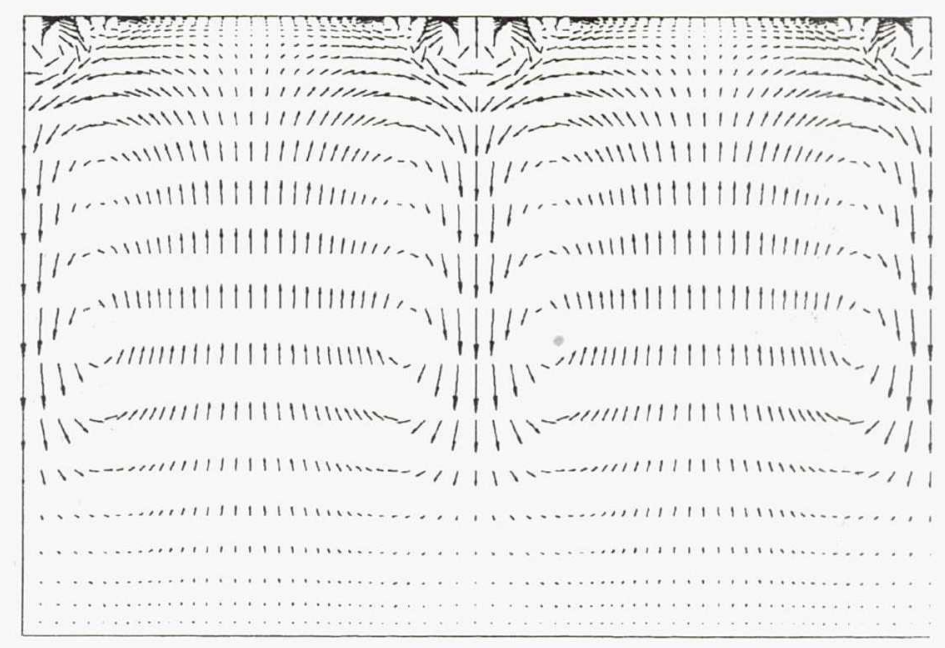

(b) $X / L=0.5$.

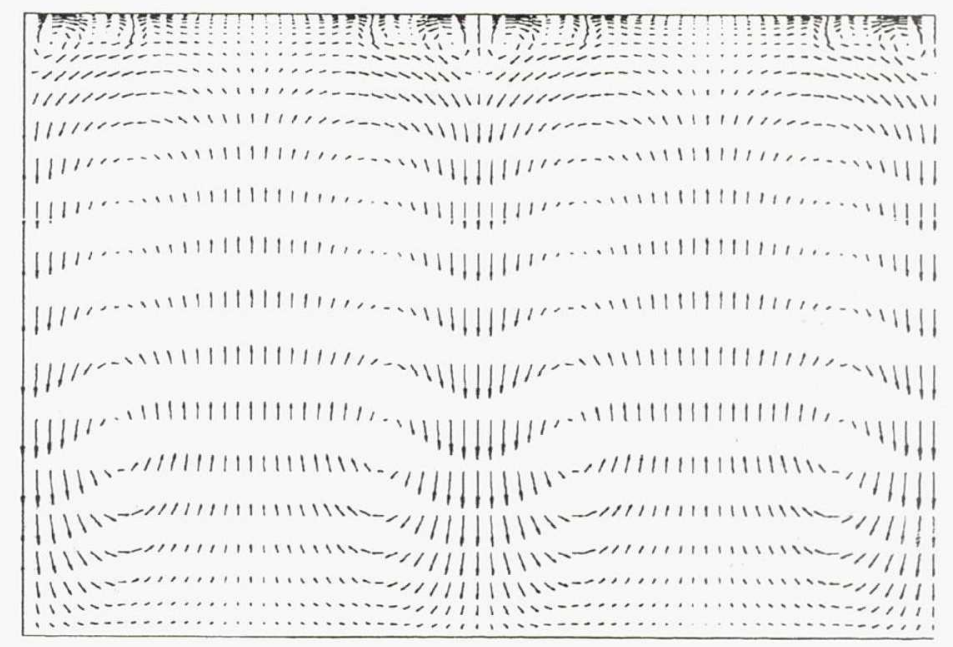

(c) $X / L=1.0$.

Figure 13.-Velocity vectors $\left(A_{\Theta} / A_{\operatorname{mix}}=1.0\right)$. 


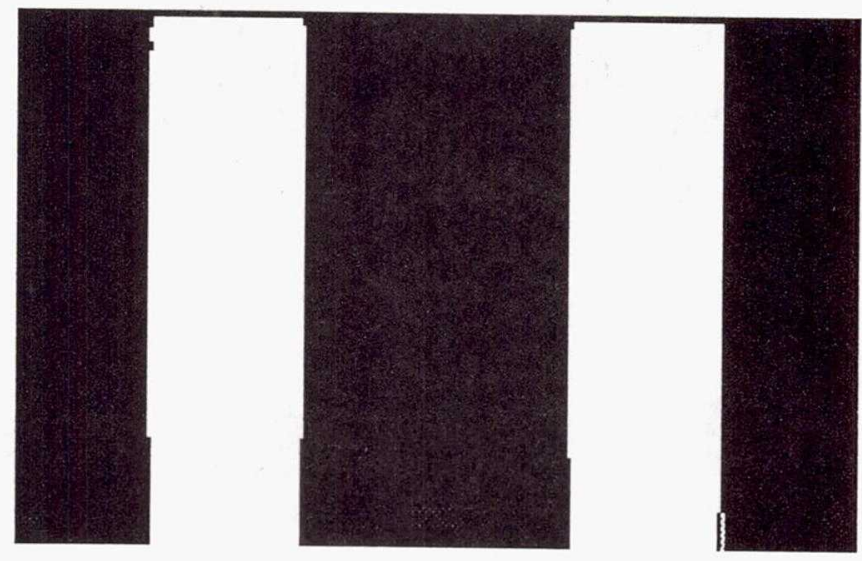

(a) $X / L=0.0$.

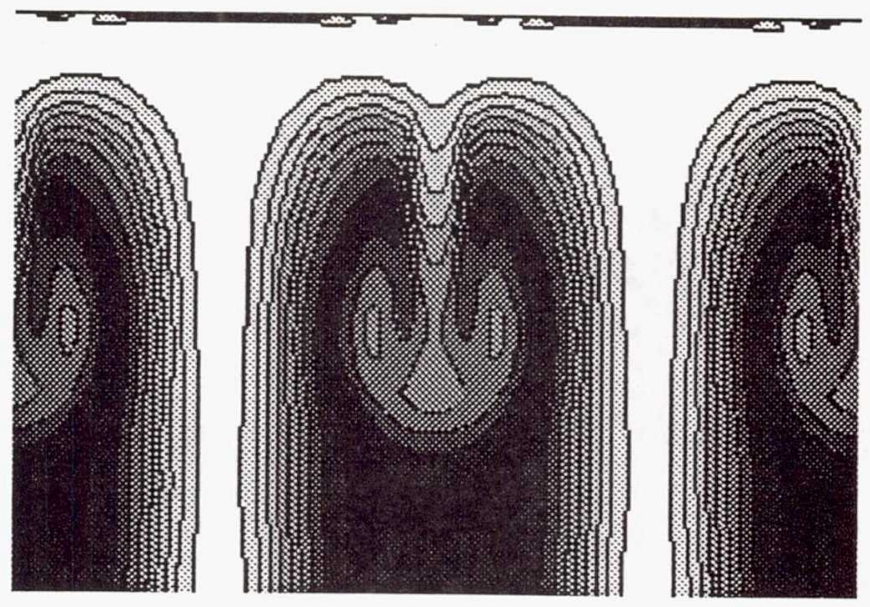

(b) $X / L=0.5$.

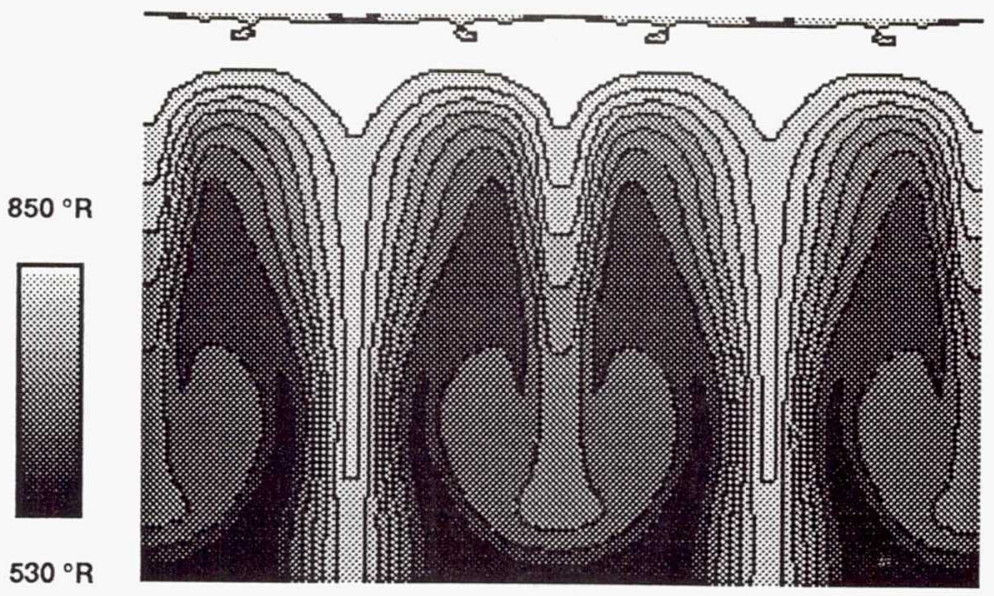

(c) $X / L=1.0$.

Figure 14.-Total temperature contours $\left(A_{\Theta} / A_{\text {mix }}=1.0\right)$. 


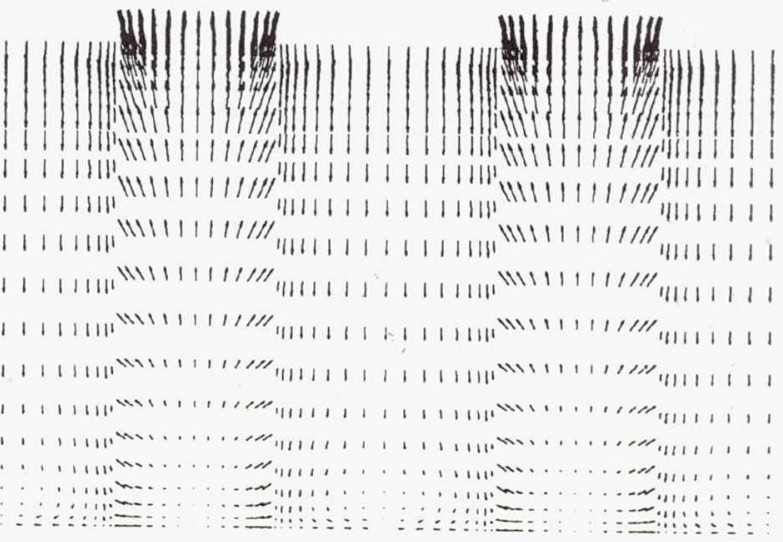

(a) $X / L=0.0$.

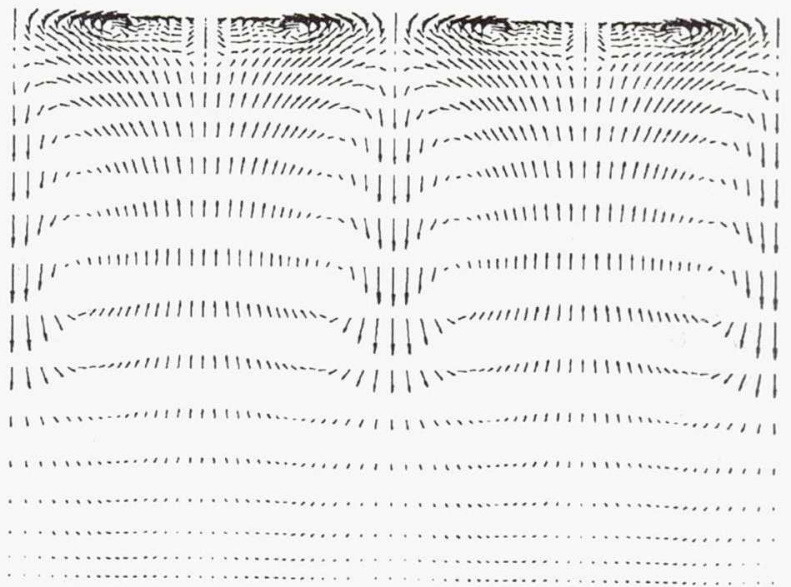

(b) $\mathrm{X} / \mathrm{L}=0.5$.

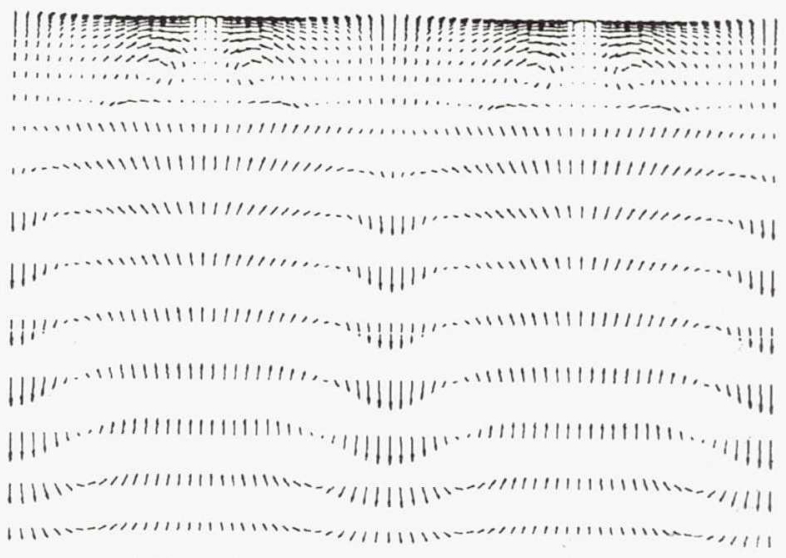

(c) $X / L=1.0$.

Figure 15. - Velocity vectors $\left(A_{e} / A_{m i x}=1.2\right)$. 


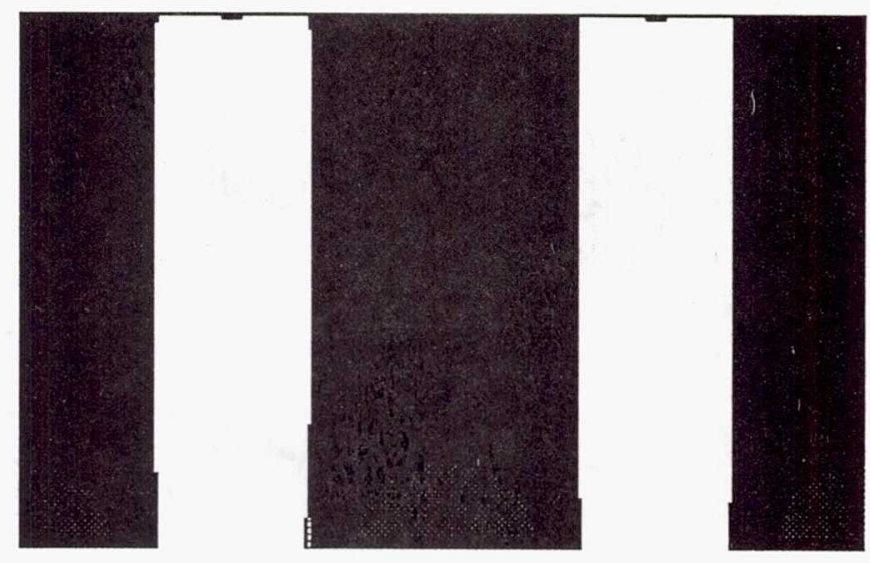

(a) $X / L=0.0$.

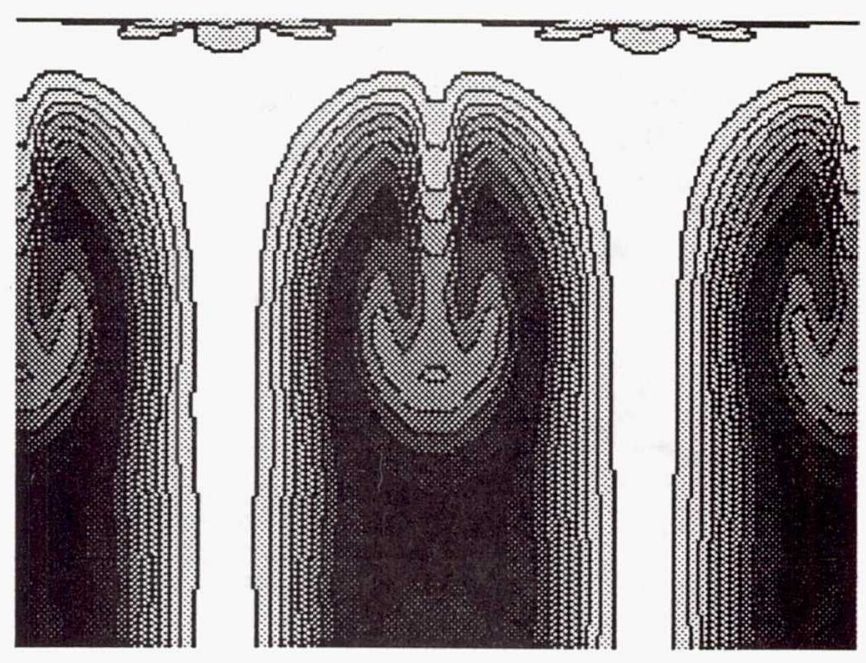

(b) $X / L=0.5$.

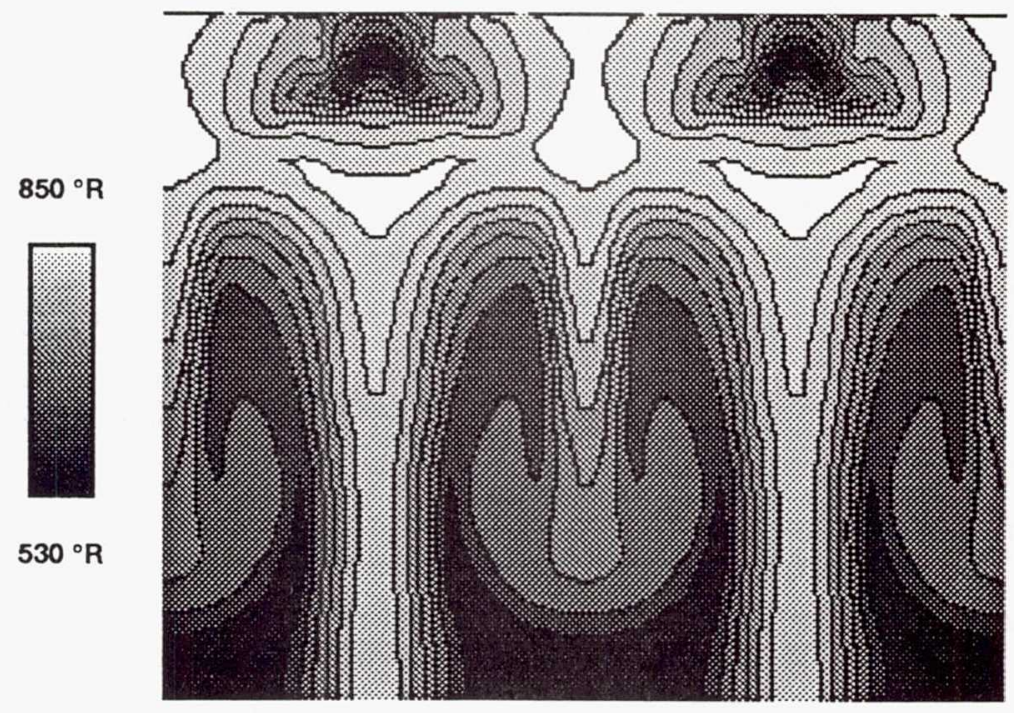

(c) $X L=1.0$.

Figure 16. -Total temperature contours $\left(A_{e} / A_{\text {mix }}=1.2\right)$. 


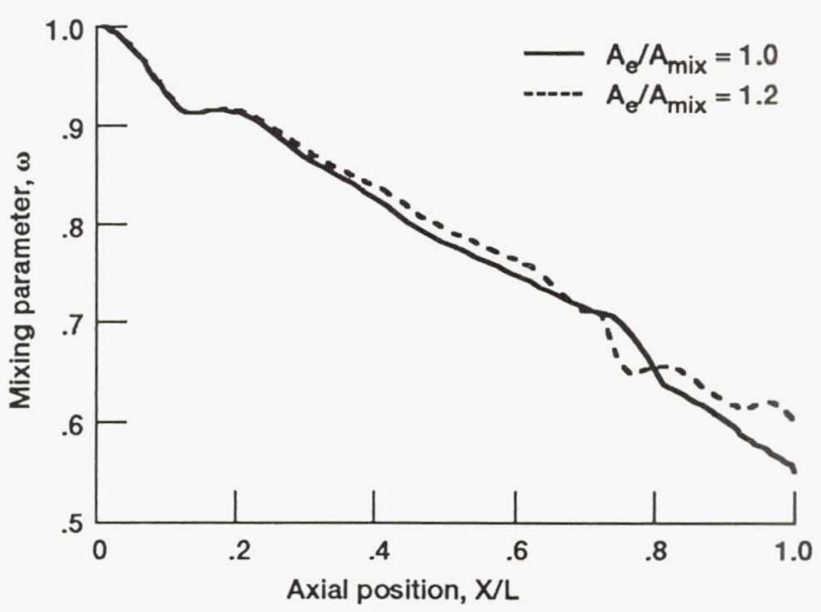

Figure 17.-Mixing parameter in mixing section.

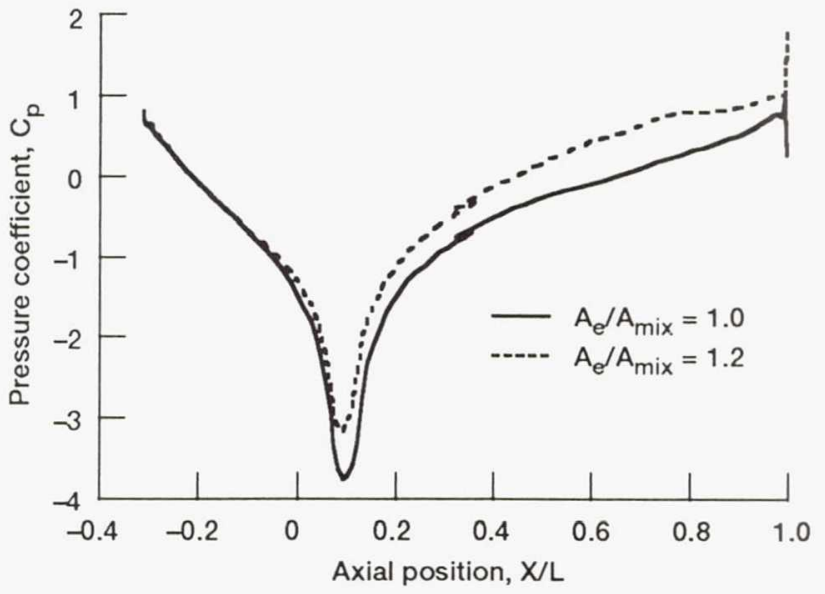

Figure 18.-Boattail pressure coefficient. 
Public reporting burden for this collection of information is estimated to average 1 hour per response, including the time for reviewing instructions, searching existing data sources, gathering and maintaining the data needed, and completing and reviewing the collection of information. Send comments regarding this burden estimate or any other aspect of this collection of information, including suggestions for reducing this burden, to Washington Headquarters Services, Directorate for information Operations and Reports, 1215 Jefferson Davis Highway, Suite 1204, Arlington, VA 22202-4302, and to the Office of Management and Budget, Paperwork Reduction Project (0704-0188), Washington, DC 20503.

\begin{tabular}{|l|l|l}
\hline 1. AGENCY USE ONLY (Leave blank) & $\begin{array}{c}\text { 2. REPORT DATE } \\
\text { July } 1992\end{array}$ & $\begin{array}{r}\text { 3. REPORT TYPE AND DATES COVERED } \\
\text { Technical Memorandum }\end{array}$ \\
\hline
\end{tabular}

\section{TITLE AND SUBTITLE}

Full Navier-Stokes Analysis of a Two-Dimensional Mixer/Ejector Nozzle

for Noise Suppression

\section{AUTHOR(S)}

James R. DeBonis
WU-537-02-23

8. PERFORMING ORGANIZATION REPORT NUMBER

E-7109

National Aeronautics and Space Administration

Lewis Research Center

Cleveland, Ohio 44135-3191

5. FUNDING NUMBERS

SPONSORING/MONITORING AGENCY NAMES(S) AND ADDRESS(ES)

10. SPONSORING/MONITORING AGENCY REPORT NUMBER

National Aeronautics and Space Administration

Washington, D.C. 20546-0001

NASA TM-105715

AIAA-92-3570

\section{SUPPLEMENTARY NOTES}

Prepared for the 28th Joint Propulsion Conference and Exhibit, cosponsored by AIAA, SAE, ASME, and ASEE, Nashville, Tennessee, July 6-8, 1992. Responsible person, James R. DeBonis, (216) 433-6581.

12a. DISTRIBUTION/AVAILABILITY STATEMENT

12b. DISTRIBUTION CODE

Unclassified - Unlimited

Subject Category 07

\section{ABSTRACT (Maximum 200 words)}

A three-dimensional full Navier-Stokes (FNS) analysis was performed on a mixer/ejector nozzle designed to reduce the jet noise created at takeoff by a future supersonic transport. The PARC3D computational fluid dynamics (CFD) code was used to study the flow field of the nozzle. The grid that was used in the analysis consisted of approximately 900000 node points contained in eight grid blocks. Two nozzle configurations were studied: a constant area mixing section and a diverging mixing section. Data are presented for predictions of pressure, velocity, and total temperature distributions and for evaluations of internal performance and mixing effectiveness. The analysis provided good insight into the behavior of the flow.

\section{SUBJECT TERMS}

Nozzles; Two dimensional; Mixer/ejector; Noise suppression

17. SECURITY CLASSIFICATION OF REPORT

Unclassified
18. SECURITY CLASSIFICATION OF THIS PAGE Unclassified
19. SECURITY CLASSIFICATION OF ABSTRACT Unclassified
15. NUMBER OF PAGES

16

16. PRICE CODE

$\mathrm{A03}$
20. LIMITATION OF ABSTRACT 